\title{
Growth hormone and idiopathic short stature - it is too soon to call it a mis-trial
}

\author{
Paul Saenger \\ Division of Pediatric Endocrinology, Albert Einstein College of Medicine/Montefiore, Medical Center, Bronx, New York, USA
}

(Correspondence should be addressed to P Saenger, Division of Pediatric Endocrinology, Montefiore Medical Center, 111 East $210 t h$ Street, Bronx, New York 10467, USA)

When the late Chinese Premier Chou En Lai was once asked what he thought about the French Revolution his cryptic answer was: 'it's too soon to tell'. Hopefully, it will not take us that long to find out whether growth hormone is of any use in the treatment of idiopathic short stature.

Children with significant short stature (height below the fifth percentile) who do not have growth hormone (GH) deficiency defined by classic criteria (GH above $10 \mathrm{ng} /$ $\mathrm{ml}$ ) are commonly referred to as having idiopathic short stature and frequently seek treatment with GH. A series of studies detailed below describe the effect of GH in a group of children who are short and have a normal GH response to stimuli but have an abnormally slow growth velocity.

Following recognition of the need for GH therapy for children who are definitely deficient in $\mathrm{GH}$, the next question is: what do we have to offer children who are short and who, following stimulatory tests, do not have definite GH deficiency? This is a difficult issue to resolve. In addition to the known limitations of radioimmunoassay measurements described above, it is possible that testing to provoke GH secretion frequently does not reflect endogenous GH secretion. Several groups who have used serial GH sampling techniques during 12-h and 24-h periods have shown a discrepancy between pharmacologic testing and spontaneous GH secretion in children who are short. The term neurosecretory dysfunction was used initially to describe this entity, because some patients diagnosed as having neurosecretory dysfunction had received cranial radiation for the treatment of systemic or head and neck malignancies. It is well known that ionizing radiation of $24 \mathrm{~Gy}$ or more will severely dampen GH output. A recent study showed, however, that healthy children of normal height and children of idiopathic short stature may have the same low GH secretory profiles as those reported for patients who have organic hypothalamicpituitary damage following irradiation. From these studies we may conclude that the physiologic approach of sampling GH every 20 min for 12 or $24 \mathrm{~h}$ is no more sensitive than provocative tests in the detection of subtle forms of GH deficiency $(1,2)$.

Accordingly, the routine measurement of spontaneous GH secretion throughout 12 or $24 \mathrm{~h}$ in the diagnosis of GH deficiency is not indicated. Although, in the case of healthy children, a positive correlation exists between profiles of $\mathrm{GH}$ secretion (as determined by frequent blood sampling techniques) and both height and height velocity, the range of overlap is large and does not allow a meaningful and reliable classification of individual patients. Because of the limited use of multiple sampling testing, this technique must be relegated to the research environment. Rather, together with clinical assessment, measurements of components of the endocrine growth axis, i.e. insulin-like growth factor-I (IGF-I), IGF binding protein-3 (IGFBP-3), and $\mathrm{GH}$ in response to provocative tests may allow a more meaningful assessment of 'IGF deficiency' $(2,3)$.

In the best of all possible worlds, the most effective response to 'heightism' is a concerted effort to reveal and rectify height prejudice and not to accede to the demand for unrestricted use of GH. Unfortunately, sympathic reassurance will satisfy only some parents, and well-intentioned counseling reinforcing the broad boundaries of normality is not successful with all families.

The best evidence that growth hormone therapy should be able to cause virtually any child to grow more rapidly and to attain a greater adult height lies in the observation that children with growth hormonesecreting pituitary tumors grow to be giants. The real questions do not relate to the efficacy of growth hormone but rather to whether increased adult height can be achieved with safe doses of growth hormone and whether such therapy is ethically justifiable and represents a suitable use of finite medical resources in an era dominated by aggressive cost containment (3).

Attenuation of the therapeutic response to GH is seen in both GH-deficient and non-GH-deficient children who are short. The therapeutic response typically wanes after the first 2-3 years. In published studies, administration of $\mathrm{GH}$ increased mean growth velocity by $2 \mathrm{~cm}$ per year in $75 \%$ of the treated healthy children who are short. The question remains whether GH may be useful for maximizing the height potential of healthy patients who are extremely short. The increase in growth velocity has not been as great as seen in classic $\mathrm{GH}$ deficiency, where a first-year response of $10.5 \pm 2.2 \mathrm{~cm}$ 
per year is commonly seen with the same dosage of GH $(0.3 \mathrm{mg} / \mathrm{kg} /$ week $)$. This suggests that some patients who have idiopathic short stature may be less sensitive to $\mathrm{GH}$ treatment than patients who have severe $\mathrm{GH}$ deficiency (4). The same is true for the patients with achondroplasia studied by Tanaka et al. and published in this issue of the European Journal of Endocrinology. Their growth response was modest in year one and disappointing in year two (5).

There are no significant anthropometric predictors of response, including bone age deficit or parental height. Little distinction was found between the responses of children classified as having familial short stature or constitutional short stature and the responses of the entire treatment population. This observation challenges the general belief that children who have familial short stature (those who commonly have little or no bone age delay and have short parents) are not likely to respond to exogenous growth hormone. Basal IGF-I and IGFBP may correlate with GH responses to stimulation tests, but they do not aid in predicting who will respond to treatment. However, they do increase with $\mathrm{GH}$ treatment and are useful to assess compliance with therapy.

After the initial enthusiasm for GH therapy in idiopathic short stature, fueled by optimistic results reported by Hopwood et al. (6) there are now a number of reports that describe failures of growth hormone treatment to increase adult height in non-GH-deficient children with short stature. A small study by Kawai et al. (7) published early this year found that in 18 short boys GH therapy was associated with earlier onset of puberty, briefer prepubertal duration, a significant decease in height standard deviation score (SDS) for bone age during the pubertal period, and a resultant decrease in final height of almost $8 \mathrm{~cm} \mathrm{(7).}$

Hindmarsh and Brook in 1996 (8) reported that GH therapy significantly increased the final height of normal short children compared with their pre-treatment predicted height, but this change was not significant compared with that observed in a small group of matched children without therapy. A major part of the problem lies in the fact that most studies compare final height with predicted final height. Several studies have shown that final height is frequently overpredicted in idiopathic short stature boys $(9,10)$. Therapy with $\mathrm{GH}$ had no effect on the onset of puberty in Hindmarsh and Brook's study (8), but treated boys progressed slightly faster through puberty than untreated boys, which was associated with an acceleration in bone age maturation. This acceleration in bone age maturation has a negative impact on final height, because closure of the epiphyses occurs sooner. In the view of the investigators, this small increment in final height - approximately $2.8 \mathrm{~cm}$ in boys and $2.5 \mathrm{~cm}$ in girls - does not justify the widespread use of $\mathrm{GH}$ for short children. Loche et al. also reported that the GH treatment of non-GH-deficient children resulted in a faster skeletal maturation and no significant improvement on the pretreatment predicted adult height (11). In part, the disappointing results of some studies are due to the fact that the subject selection may have been less felicitous than desired. Normal short children who are growing at a near-normal growth rate may be less likely to show an accelerated growth velocity response after GH. On the other hand, normal short children with phenotypes most resembling those of GHdeficient children (poor growth rate, low IGF-I, low IGFBP-3, markedly delayed bone age, and height more than -2 SDS) may be more responsive.

The 69 idiopathic short stature patients in the Genentech study (12) had mean pretreatment heights and initial predicted heights of more than 2 s.D. below the mean for chronological age. These patients have now been treated for up to 9 years. Many have reached final height. GH therapy increased mean growth rate, height SDS, and Bayley-Pinneau predicted adult height (PAH). The mean difference between pretreatment $\mathrm{PAH}$ and final height was $4.9 \pm 4.9 \mathrm{~cm}$ for males and $5.7 \pm 5.2$ for females. The average gain was $9.1 \mathrm{~cm}$ for males and $5.6 \mathrm{~cm}$ for females compared with untreated controls. The gains resulting from GH therapy represent statistically significant increases of approximately one standard deviation $(5 \mathrm{~cm})$ in final PAH (see Table 1). However, they still remained significantly below their mid-parental target heights as a group, with a mean final height which was 0.5 s.D. below the mean midparental target height. In this study as in the multicenter study by Bernasconi et al. (13) neither onset nor

Table 1 Effect of growth hormone treatment in idiopathic short stature: differences in final height and predicted adult height (PAH).

\begin{tabular}{|c|c|c|c|c|c|c|}
\hline \multirow[b]{2}{*}{ Study } & \multirow[b]{2}{*}{ Number } & \multirow{2}{*}{$\begin{array}{l}\text { Years of } \\
\text { therapy }\end{array}$} & \multicolumn{2}{|c|}{$\begin{array}{l}\text { Change in final height/PAH } \\
(\mathrm{cm} \pm \text { S.D. })\end{array}$} & \multicolumn{2}{|c|}{$\begin{array}{l}\text { Mean change in final height } \\
\text { untreated short controls } \\
(\mathrm{cm})(\leq 2 \text { S.D. })\end{array}$} \\
\hline & & & Females & Males & Females & Males \\
\hline Hintz et al. (12) & 61 & $2-9$ & $5.7 \pm 5.2$ & $4.9 \pm 4.9$ & 5.6 & 9.1 \\
\hline Loche et al. (11) & 15 & $4-10$ & None & None & ND & ND \\
\hline Hindmarsh \& Brook (8) & 9 & $4-9$ & 2.5 & 2.8 & ND & ND \\
\hline Kawai et al. (7) & $16^{*}$ & $3.2-5$ & - & -8.6 & ND & ND \\
\hline
\end{tabular}

*Boys only; ND, not done. 
tempo of puberty was significantly accelerated. It is, however, entirely conceivable that an increased tempo of puberty may be more likely in those patients who are treated with higher doses of growth hormone. It is also quite possible that those with more significant bone age advancement had higher serum estradiol levels. With more sensitive methods for estradiol determinations in prepubertal boys and girls now available these questions may be succinctly addressed in the near future. Therapy should thus best be targeted to patients with a low initial adult height prediction at a younger age presentation, because they have a poorer height outcome as a group. It may not be applicable to older patients with a normal predicted adult height (14).

The paper by Tanaka et al. (5) in this issue describing the effect of growth hormone therapy in children with achondroplasia is marred by the fact that there was, in fact, no contemporaneous or historical control group and that the study was not carried out to at or near final height. While growth hormone therapy increased growth velocity during treatment in the first year, it is not at all surprising that height gain in the second year was already quite modest. In most countries treatment of hypo- or achondroplasia with growth hormone is not an approved indication. I am not intoning now the mantra for 'double-blind placebo-controlled trials to final height in hypo- and achondroplasia'. It is not going to happen in the USA because many ethics boards will not approve such trials and it is unlikely to happen elsewhere. We are also naive if we think that results of a double-blind placebo-controlled trial to final height for idiopathic short stature will come anytime soon. In achondroplasia it is about as likely as a placebo-controlled trial of acupuncture. It may be best to follow Professor Brook's adage to 'save the money allocated for growth hormone and spend it all on a successful leg lengthening procedure' (C G D Brook, personal communication) when the time is right and a good surgeon is available.

While no final recommendation as far as therapeutic intervention with GH in normal short children can be offered, studies do suggest the potential efficacy in some short children, but not necessarily in those with skeletal dysplasias. These children show an acceleration in growth rate and a significant improvement in adult height. In normal short children, particularly those with normal growth velocities, therapy with higher doses of growth hormone may lead to more rapid pubertal progression, negating any potential effect on adult height. GH treatment is certainly not indicated in the older short adolescent who has completed $95 \%$ of his or her growth. GH will simply not improve adult height. In the typical patient with constitutional delay of puberty and short stature and normal GH and IGF-I levels, watchful waiting is best. If puberty is delayed beyond age 15 in boys, testosterone or oxandrolone is a safe, reasonable, and cheap therapeutic alternative.
While GH treatment is of proven benefit in some nonGH-deficient patients with idiopathic short stature $(\gg-2$ S.D. ) who are treated early, well before puberty, the decision to use GH in idiopathic short stature is a complex issue that must involve accurate diagnosis of an abnormality in the GH/IGF axis and a candid discussion of the potential risks and benefits to the patient.

It is important to stress that there is little data to suggest that short pre-pubertal children are psychosocially maladjusted, despite the vociferous protestations of their parents $(15,16)$. Similarly, it has not been shown that growth hormone treatment improves psychosocial adjustment in short non-GH-deficient prepubertal children, although numerous psychologic aspects of adolescence may be related to stature and timing of sexual development (17). In overweight, short adolescents and young adults, however, earning capacity was adversely affected by height and ponderosity (18). In addition, to an analysis of psychosocial benefits in the USA, the cost of treatment must be considered. In the USA one year of therapy may easily cost \$25000. Each millimeter in height gain may thus cost more than $\$ 1000$ (19). These widespread concerns only fan our hopes that oral nonpeptide GH secretagogues may be much cheaper once they are proven effective and approved for use in children (20).

\section{References}

1 Bercu BB, Shulman D, Root AW \& Spiliotis B. Growth hormone provocative testing frequently does not reflect endogenous growth hormone secretion. Journal of Clinical Endocrinology and Metabolism $198663709-716$.

2 Rosenfeld RG, Albertsson-Wikland K, Cassorla F, Frasier SD, Hasegawa Y, Hintz RL et al. Diagnostic controversy: the diagnosis of childhood growth hormone deficiency revisited. Journal of Clinical Endocrinology and Metabolism 199580 1532-1540.

3 Rosenfeld RG. Editorial: Is growth hormone just a tall story? Journal of Pediatrics $1997130172-173$.

4 Lesage C, Walker J, Landier F, Chatelain P, Chaussain JL \& Bougnerès PF. Near normalization of adolescent height with growth hormone therapy in very short children without growth hormone deficiency. Journal of Pediatrics 199111929.

5 Tanaka H, Kubo T, Yamate T, Ono T, Kanzaki S \& Seino Y. Effect of growth hormone therapy in children with achondroplasia: growth pattern, hypothalamic-pituitary function, and genotype. European Journal of Endocrinology 1998138 275-280.

6 Hopwood NJ, Hintz RL, Gertner JM, Attie KM, Johanson AJ \& Baptista J. Growth response of non-growth hormone-deficient children with marked short stature during three years of growth hormone therapy. Journal of Pediatrics 1993123 215-222.

7 Kawai M, Momoi T, Yorifuji T, Yamanaka C, Sasaki H \& Furusho K. Unfavorable effects of growth hormone therapy on the final height of boys with short stature not caused by growth hormone deficiency. Journal of Pediatrics 1997130 205-209.

8 Hindmarsh PC \& Brook CGD. Final height of short normal children treated with growth hormone. Lancet 1996348 13-16.

9 Price DA. Spontaneous adult height in patients with idiopathic short stature. Hormone Research (Suppl 2) 199645 59-63.

10 LaFranchi S, Hanna CE \& Mandel SH. Constitutional delay of growth: expected versus final adult height. Pediatrics 1990117 $16-21$.

11 Loche S, Cambiaso P, Setzu S, Carta D, Marini R, Borelli P et al. 
Final height after growth hormone therapy in non-growth hormone-deficient children with short stature. Journal of Pediatrics 1994125 196-200.

12 Hintz RL, Attie KM, Saenger P, Johanson A, Baptista J, Kuntze J et al. Use of growth hormone for growth promotion of growth in idiopathic short stature children: final height results of the US Study. Hormone Research 199748 (Suppl 2) 18.

13 Bernasconi S, Street ME, Volta C \& Mazzardo G and the Italian Multicenter Study Group. Final height in non-growth hormonedeficient children treated with growth hormone. Clinical Endocrinology 199747 261-266.

14 Ranke MB, Grauer ML, Kistner K, Blum WF \& Wolmann HA Spontaneous adult height in idiopathic short stature. Hormone Research 199544 152-157.

15 Skuse D, Gilmour J, Tian CS \& Hindmarsh P. Psychosocial assessment of children with short stature. Acta Paediatrica Scandinavica (Suppl) 1994406 11-16.

16 Brook CGD. Final height in non-growth hormone deficient children. Clinical Endocrinology 199747267.
17 Cuttler L, Michon R, Reinecke M \& Stocking C. Attitudinal and behavior concomitants of short stature. Pediatric Research 1990 $274 \mathrm{~A}$.

18 Sargent JD \& Blanchflower DG. Obesity and stature in adolescence and earnings in young adulthood. Archives of Pediatrics and Adolescent Medicine 1994148 681-687.

19 Saenger P. Growth hormone treatment for children without growth hormone deficiency. Does it work and will it produce adolescents who are better adjusted? Adolescent Medicine: State of the Art Reviews 19978 527-536.

20 Saenger P. Editorial: Oral growth hormone secretagogues - better than Alice in Wonderland's growth elixir. Journal of Clinical Endocrinology and Metabolism 199681 2773-2775.

Received 10 December 1997

Accepted 15 December 1997 